\title{
A FIVE YEAR RETROSPECTIVE STUDY OF MATERNAL MORTALITY AT RAJENDRA INSTITUTE OF MEDICAL SCIENCES, RANCHI, JHARKHAND IN THE YEAR 2011 TO 2015
}

\author{
Kiran Trivedi1, Ritika Prakash²
}

${ }_{1}^{1}$ Assistant Professor, Department of Obstetrics and Gynaecology, Rajendra Institute of Medical Sciences, Ranchi, Jharkhand. ${ }^{2} 3^{\text {rd }}$ Year Junior Resident, Department of Obstetrics and Gynaecology, Rajendra Institute of Medical Sciences, Ranchi, Jharkhand.

\section{ABSTRACT}

\section{BACKGROUND}

Maternal health is an important determinant of a country's growth and development. This study was done to evaluate the maternal mortality ratio in our hospital RIMS, Ranchi, Jharkhand, to assess the epidemiological aspects and causes of maternal mortality and to recommend preventive measures to reduce maternal deaths.

\section{METHODS}

This was a 5-year retrospective study. Data was collected from maternal mortality register of the hospital after permission from the medical superintendent of RIMS.

\section{RESULTS}

A total of 376 deaths occurred against 63088 live births in the time span of 2011-2015 at RIMS, Ranchi. MMR was calculated to be 595.99 per 100000 live births; $69.14 \%$ of all maternal deaths were due to direct causes. Pregnancy induced hypertension was found to be the most important cause accounting for $36.97 \%$ of all maternal deaths with antepartum eclampsia accounting for $25.8 \%$ followed by Haemorrhage contributing to $14.89 \%$ of all maternal deaths amongst which postpartum haemorrhage (11.44\%) was more common. Maximum maternal deaths (53.72\%) were reported in the age group of 21 to 29 years with more deaths in multiparous women (49.47\%) with maximum deaths (50\%) in the postpartum period.

\section{CONCLUSION}

Improvement in health care services, strengthening of referral systems, better training of health care workers and most importantly creating awareness among rural population towards female health can go a long way in upgrading maternal health status in Jharkhand.

\section{KEYWORDS}

Maternal Mortality, Prevention, Maternal Death

HOW TO CITE THIS ARTICLE: Trivedi K, Prakash R. A five year retrospective study of maternal mortality at Rajendra Institute of Medical Sciences, Ranchi, Jharkhand in the year 2011 to 2015. J. Evolution Med. Dent. Sci. 2016;5(74):5451-5455, D0I: 10.14260/jemds/2016/1234

\section{INTRODUCTION}

In India, especially in Jharkhand where optimal health care facilities are still in its infancy, a healthy mother and a healthy baby is still a goal to be embraced in all health programmes and Government implementations. According to FIGO, maternal mortality is defined as "women dying while pregnancy or within forty two days of termination of pregnancy by any means irrespective of duration and site of pregnancy from any cause related to or aggravated by pregnancy or its management, but not from accidental or incidental causes."

Direct obstetric deaths are "those resulting from obstetric complications of the pregnant state (Pregnancy, labour and puerperium) from interventions, omissions, incorrect treatment or from a chain of events resulting from any of the above."

Financial or Other, Competing Interest: None.

Submission 02-08-2016, Peer Review 31-08-2016,

Acceptance 07-09-2016, Published 14-09-2016.

Corresponding Author:

Dr. Kiran Trivedi,

C/o. Rama Nursing Home, Main Road,

Opposite G.E.L Church Complex,

Ranchi-834001,

Jharkhand.

E-mail: trivedikiran2011@gmail.com

DOI: $10.14260 /$ jemds/2016/1234

\section{(c) (1) $(9$}

Indirect obstetric deaths are "those resulting from previous existing disease or disease that developed during pregnancy and which was not due to direct obstetric causes, but which was aggravated by physiologic effects of pregnancy."

Maternal mortality ratio measures "number of woman aged 15-49 years dying due to maternal causes per $1,00,000$ live births."

As data given by census of India, 2010-2012, Ministry of Home Affairs, Government of India, maternal mortality ratio in India is 178 per $1,00,000$ live births, whereas in Jharkhand it is 219 per $1,00,000$ live births and maternal mortality rate in India is 12.4 per $1,00,000$ women of reproductive age group, whereas in Jharkhand it is 22.8 per $1,00,000$ women of reproductive age group. [1] The tragedy is that these deaths are largely preventable. National Rural Health Mission (NRHM) had a target to reduce MMR to $100 / 100,000$ by 2012.[2] Millennium Development Goal 5 had an aim to reduce MMR by three quarters between 1990 and 2015.[3] India has observed appreciable decline in MMR from 677 in 1980 to 254 in 20042006, 212 in 2007-2009 and to 178 in 2010-2012. The advance is largely due to key government interventions, such as the Janani Shishu Suraksha Karyakaram (JSSK) scheme which encompasses free maternity services for women and children, a nationwide scale up of emergency referral systems and maternal health audits and improvements in the governance and management of health services at all levels [UNICEF INDIA]. 
Every two minutes a woman dies of pregnancy related complications, the four most common causes being: Severe bleeding after childbirth, infections, high blood pressure during pregnancy and unsafe abortion. ${ }^{[4]}$ According to a report published in The Times of India, June 2016, a pregnant woman is dying every 5 minutes in India.

The study was done to assess maternal mortality at RIMS, a Medical College Hospital situated at Ranchi, Jharkhand, which is a tertiary referral centre for semi-urban and rural areas of Jharkhand.

\section{AIMS AND OBJECTIVES}

1. To calculate the maternal mortality ratio at RIMS in the year 2011-2015.

2. To analyse the epidemiological factors related to maternal health.

3. To evaluate the causes of maternal mortality including direct and indirect causes.

4. To recommend appropriate measures to improve maternal health and reduce mortality.

\section{MATERIALS AND METHODS}

RIMS is a semi-urban, tertiary care centre situated in Jharkhand. It gets a large number of referrals from maternity homes, primary health centres, community health centres, Sadar Hospitals from rural parts of Jharkhand. The present study was a retrospective study, conducted in the Department of Obstetrics and Gynaecology at RIMS. Data regarding maternal mortality was collected from maternal mortality register after obtaining permission from the medical superintendent of RIMS.

A Detailed Study was done with Emphasis on the Following Factors

- Demographic distribution of maternal deaths.

- Distribution of maternal deaths according to socioeconomic profile.

- Distribution of maternal deaths according to obstetrical history including parity and mode of previous deliveries.

- Distribution of maternal deaths according to awareness and accessibility to antenatal care.

- Causes of maternal deaths including direct and indirect ones.

- A qualitative and quantitative analysis of data was made and tabulated. Maternal Mortality Ratio (MMR) was calculated for the year 2011-2015 and its causes were analysed.

MMR - Total no. of maternal deaths/Total no. of live births $* 100000$.

\section{RESULTS}

In the present study, following parameters were observed in the years 2011 to 2015 .

\begin{tabular}{|c|c|c|}
\hline Year & $\begin{array}{c}\text { No. of Maternal } \\
\text { Deaths }\end{array}$ & $\begin{array}{c}\text { No. of Live } \\
\text { Births }\end{array}$ \\
\hline $\begin{array}{c}2011- \\
2015\end{array}$ & 376 & 63088 \\
\hline \multicolumn{2}{|c|}{ Table 1: Number of Maternal Deaths } \\
\hline
\end{tabular}

There were 376 maternal deaths out of 63088 live births in the years 2011-2015. MMR was calculated to be 595.99 per 100000 live births.

\begin{tabular}{|c|c|}
\hline Age & $\mathbf{2 0 1 1 - 2 0 1 5}$ \\
\hline < 20 years & $88(23.40 \%)$ \\
\hline 21 to 29 years & $202(53.72 \%)$ \\
\hline 30 years and above & $86(22.87 \%)$ \\
\hline Total & $\mathbf{3 7 6}$ \\
\hline Table 2: Maternal Death Distribution According to Age \\
\hline
\end{tabular}

Maximum deaths [53.72\%] were reported in the age group of 21 to 29 years.

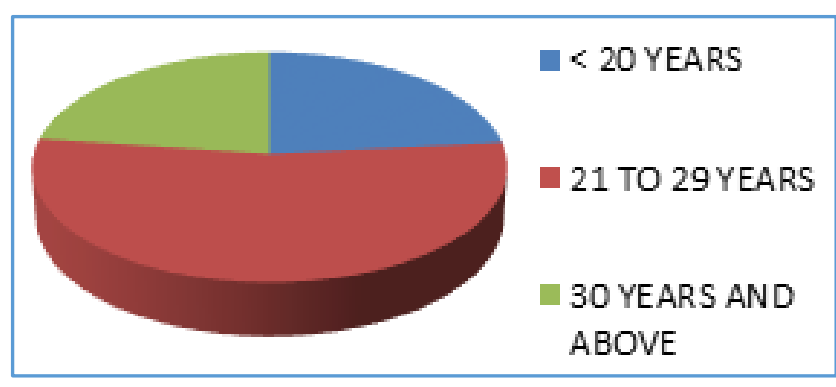

\begin{tabular}{|c|c|}
\hline $\begin{array}{c}\text { Socioeconomic } \\
\text { Status }\end{array}$ & $\mathbf{2 0 1 1 - 2 0 1 5}$ \\
\hline Low & $365(97.07 \%)$ \\
\hline Middle & 11 \\
& $(2.93 \%)$ \\
\hline Total & $\mathbf{3 7 6}$ \\
\hline \multicolumn{2}{|c|}{ Mable 3: Socioeconomic Status Affecting } \\
\hline
\end{tabular}

Maximum cases [97.07\%] of maternal deaths belonged to low socioeconomic status.

\begin{tabular}{|c|c|}
\hline Locality & $\mathbf{2 0 1 1 - 2 0 1 5}$ \\
\hline Rural & $213(56.65 \%)$ \\
\hline Semiurban & $111(29.52 \%)$ \\
\hline Urban & $52(13.83 \%)$ \\
\hline Total & $\mathbf{3 7 6}$ \\
\hline Table 4: Distribution of Maternal Deaths as per Locality \\
\hline
\end{tabular}

Maximum deaths [56.65\%] were in patients from rural areas.

\begin{tabular}{|c|c|}
\hline & $\mathbf{2 0 1 1 - 2 0 1 5}$ \\
\hline Tribal Population & $106(28.1 \%)$ \\
\hline $\begin{array}{c}\text { Non-Tribal } \\
\text { Population }\end{array}$ & $270(71.8 \%)$ \\
\hline Table 5: Distribution of Deaths as per Tribal Population \\
\hline
\end{tabular}

Maximum maternal deaths [71.8\%] were reported in women of non-tribal population.

\begin{tabular}{|c|c|}
\hline Religion & $\mathbf{2 0 1 1 - 2 0 1 5}$ \\
\hline Hindu & $267(71.01 \%)$ \\
\hline Muslim & $69(18.35 \%)$ \\
\hline Christian & $40(10.64 \%)$ \\
\hline \multicolumn{2}{|c|}{$\mathbf{3 7 6}$} \\
\hline Table 6: Distribution of Maternal Deaths as per Religion \\
\hline
\end{tabular}

Maximum maternal deaths [71.01\%] were in women of Hindu religion.

\begin{tabular}{|c|c|}
\hline Parity & 2011-2015 \\
\hline Primi & $120(31.91 \%)$ \\
\hline $\begin{array}{l}\text { Multipara } \\
\text { (Para 1-4) }\end{array}$ & $186(49.47 \%)$ \\
\hline Grand Multipara (5 and Above) & $70(18.62 \%)$ \\
\hline & 376 \\
\hline
\end{tabular}

Maximum maternal deaths [49.47\%] were reported in multiparous women. 


\begin{tabular}{|c|c|}
\hline Mode of Delivery & 2011-2015 \\
\hline Undelivered & $109(28.99 \%)$ \\
\hline Vaginal Delivery & $175(46.54 \%)$ \\
\hline LSCS, Laparotomy (Rupture Uterus) & $61(16.22 \%)$ \\
\hline Abortion & $31(8.24 \%)$ \\
\hline \multicolumn{2}{|c|}{ Table 8: Maternal Death Distribution as } \\
per Mode of Delivery \\
\hline
\end{tabular}

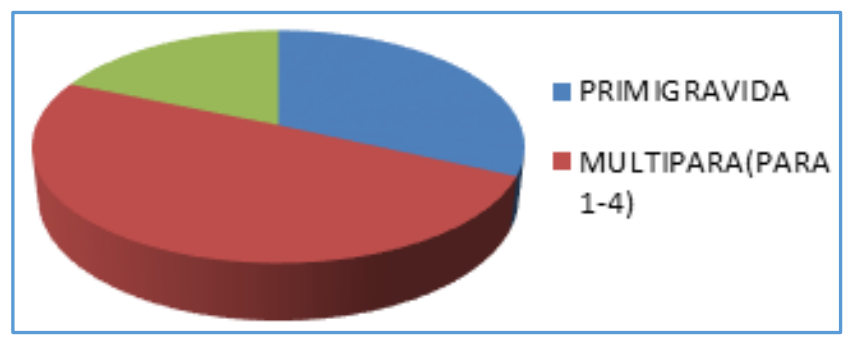

Maximum maternal deaths [46.54\%] occurred after vaginal delivery.

\begin{tabular}{|c|c|}
\hline ANCs & $\mathbf{2 0 1 1 - 2 0 1 5}$ \\
\hline No ANC & $307(81.65 \%)$ \\
\hline Irregular ANCs & $65(17.29 \%)$ \\
\hline Regular ANCs & $4(1.06 \%)$ \\
\hline \multicolumn{2}{|c|}{ 376 } \\
\hline \multicolumn{2}{|c|}{ Table 9: Effect of Antenatal Check-Ups } \\
on Maternal Mortality \\
\hline
\end{tabular}

$81.65 \%$ of cases of maternal deaths were in women who had no previous antenatal check-ups.

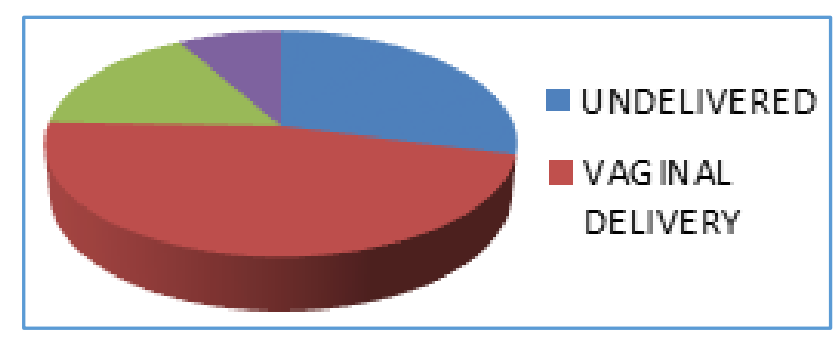

\begin{tabular}{|c|c|}
\hline Period of Pregnancy & $\mathbf{2 0 1 1 - 2 0 1 5}$ \\
\hline Below 12 Weeks & $18(4.79 \%)$ \\
\hline 12 to 40 Weeks & $170(45.21 \%)$ \\
\hline Postpartum & $188(50 \%)$ \\
\hline \multicolumn{2}{|c|}{ Table 10: Maternal Death Distribution According to } \\
Period of Pregnancy \\
\hline
\end{tabular}

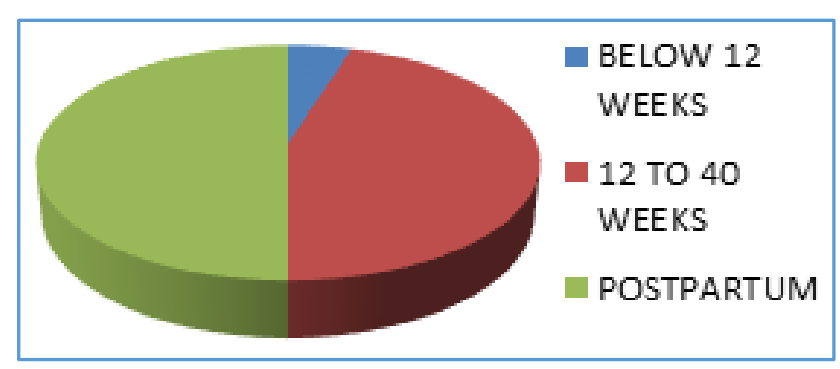

Maximum maternal deaths [50\%] were reported in the postpartum period.

\begin{tabular}{|c|c|}
\hline Marital Status & $\mathbf{2 0 1 1 - 2 0 1 5}$ \\
\hline Married & $372(98.94 \%)$ \\
\hline Unmarried & $4(1.06 \%)$ \\
\hline Table 11: Marital Status of Mortality Cases \\
\hline
\end{tabular}

Most cases [98.94\%] of maternal deaths were seen in the married population.

\begin{tabular}{|l|c|c|}
\hline \multicolumn{1}{|c|}{ Direct Causes } & $\begin{array}{c}\text { 2011- } \\
\mathbf{2 0 1 5}\end{array}$ & $\begin{array}{c}\mathbf{2 0 1 1 -} \\
\mathbf{2 0 1 5}\end{array}$ \\
\hline 1) Haemorrhage & 56 & $14.89 \%$ \\
a) APH & 13 & $3.46 \%$ \\
b) PPH & 43 & $11.44 \%$ \\
\hline 2) Pregnancy Induced & 139 & $36.97 \%$ \\
Hypertension [PIH] & 21 & $5.59 \%$ \\
a) Severe PIH & 97 & $25.8 \%$ \\
b) Antepartum Eclampsia & 21 & $5.59 \%$ \\
C) Postpartum Eclampsia & 35 & $9.3 \%$ \\
\hline 3) Septicaemia & 12 & $3.19 \%$ \\
a) Post-Abortal & 23 & $6.12 \%$ \\
b) Post-Partum & 17 & $4.52 \%$ \\
\hline 4) Rupture Uterus & 4 & $1.06 \%$ \\
\hline 5) Ectopic Pregnancy & 3 & $0.8 \%$ \\
\hline 6) Molar Pregnancy & 6 & $1.60 \%$ \\
\hline 7) Obstructed Labour & \multicolumn{2}{|c|}{ Table 12: Causes of Maternal Mortality } \\
\hline \multicolumn{2}{|c|}{} \\
\hline
\end{tabular}

\begin{tabular}{|l|c|c|}
\hline Indirect Causes & $\begin{array}{c}\mathbf{2 0 1 1 -} \\
\mathbf{2 0 1 5} \\
\text { 1) Anaemia }\end{array}$ & $\begin{array}{c}\mathbf{2 0 1 1 -} \\
\mathbf{2 0 1 5} \\
\end{array}$ \\
\hline 2) Heart Disease & 9 & $22.07 \%$ \\
\hline 3) Jaundice & 5 & $1.33 \%$ \\
\hline 4) Acute Renal Failure[ARF] & 6 & $1.60 \%$ \\
5) Disseminated Intravascular & 11 & $2.93 \%$ \\
Coagulation [DIC] & 10 & $2.66 \%$ \\
\hline 6) Malaria & 7 & $1.86 \%$ \\
7) Pulmonary Embolism & 2 & $0.53 \%$ \\
\hline 8) Uterine Inversion & 3 & $0.80 \%$ \\
9) Uterine Perforation & 3 & $0.80 \%$ \\
10) Anaesthesia Complications & 3 & $0.80 \%$ \\
\hline 11) Drug Hypersensitivity & 2 & $0.53 \%$ \\
12) Cerebrovascular Accident & 23 & $6.12 \%$ \\
\hline 13) Others & 23 & $6.12 \%$ \\
14) Undiagnosed & \multicolumn{2}{|c|}{} \\
\hline
\end{tabular}

\section{CAUSES OF MATERNAL MORTALITY}

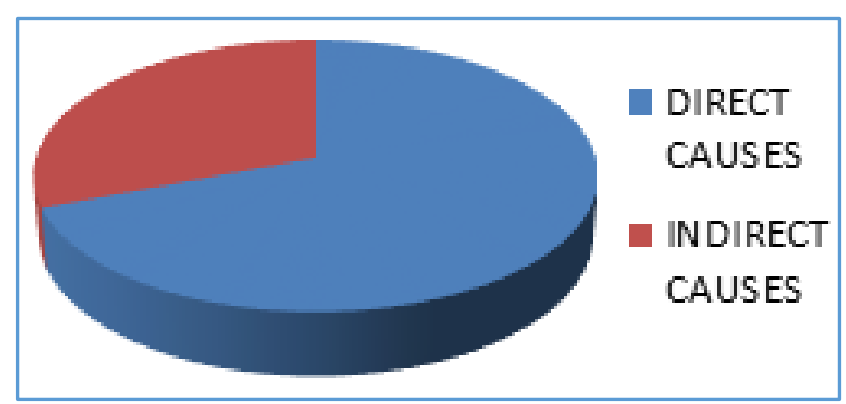




\section{DIRECT CAUSES OF MATERNAL MORTALITY}
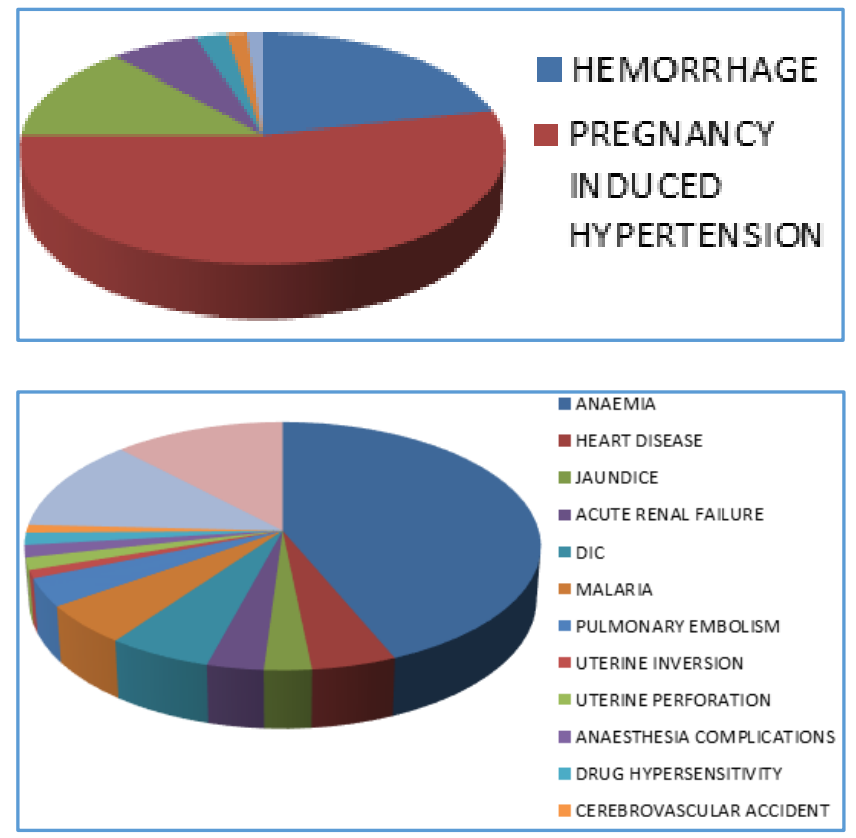

\section{INDIRECT CAUSES OF MATERNAL MORTALITY}

In the study period of 2011-2015, there were a total of 376 maternal deaths and 63088 live births. The mean mortality ratio was calculated as 595.99/100000 live births. As far as the epidemiological characteristics are concerned, maximum maternal deaths (53.72\%) were reported in the age group of 21 to 29 years. More deaths were reported in multiparous women (49.47\%) with maximum deaths (50\%) in the postpartum period. Amongst all deaths, $71.01 \%$ were reported in Hindu females of non-tribal origin (71.8\%), mostly (97.07\%) belonging to low socioeconomic strata and $56.65 \%$ were from rural areas. As expected maximum mortality $(81.65 \%)$ was seen in un-booked pregnant females with no antenatal check-ups.

On analysing the underlying causes, $69.14 \%$ of all maternal deaths were due to direct causes. Pregnancy induced hypertension was found to be the most important cause accounting for $36.97 \%$ of all maternal deaths, antepartum eclampsia making the major chunk $(25.8 \%)$ followed by Haemorrhage contributing to $14.89 \%$ of all maternal deaths, amongst which postpartum haemorrhage was more common $(11.44 \%)$. Septicaemia was found to be the third most important cause leading to $9.3 \%$ of all maternal deaths, mostly postpartum septicaemia. Ruptured uterus was found as the underlying cause in $4.52 \%$ of maternal deaths. Amongst the indirect causes, Anaemia was the most prevalent one leading to $22.1 \%$ of all maternal deaths. Heart disease, jaundice and ARF accounted for $2.39 \%, 1.33 \%$ and $1.60 \%$ of maternal deaths each respectively.

\section{DISCUSSION}

Maternal mortality is considered as the yardstick of a country's progress and development. The mean mortality ratio in the year 2011-2015 was found to be 595.99/100000 live births in the present study. The current maternal mortality ratio in India is $178 / 100000$ live births ${ }^{[1]}$ and in Jharkhand it is $219 / 100000$ live births. [1] Maternal mortality as a research topic has been a hot issue amongst statisticians, not only in India but also across the world. Various studies have documented different MMRs varying from 47/100000,[5]
$277 / 100,000,{ }^{[6]} \quad 302.23 / 100,000,[7] \quad 320 / 100,000,[8]$ 454/100,000,[9] 596.29/100,000,[10] 623.46/100,000[11] live births in India. Madhu Jain has reported a very high MMR of 2270/100000 live births.[12] There were similarities in the analysis of epidemiological factors and causes of maternal mortality as mentioned in our study with that of the study done by Murthy and Prabhu.[7] A high MMR has been reported in our study, similar to the FOGSI study on maternal mortality [MMR-596], 2005-2007, done by Hiralalkonar and Asit Baran Chakraborty ${ }^{[10]}$ because RIMS is the only tertiary health care referral centre in an underdeveloped state like Jharkhand. High risk and complicated patients pour in at RIMS from every remote nook and corner of Jharkhand, mostly in late stages when the damage is already irreversible. The classical triad of eclampsia, haemorrhage and sepsis was on the forefront in the list of causes similar to the study done by Murthy and Prabhu.[7] The paradigm of the scenario is that poor standards of living, lack of awareness towards female health, inaccessibility to adequate resources and most importantly gross negligence towards female upbringing and healthcare is still prevalent despite crores of money being engrossed in Government Health Care and Welfare Programmes.

\section{CONCLUSION}

Maternal health in the present scenario is much far from the standards set to be achieved in Government Programmes and Agendas. The causes are largely preventable, but require a unified approach and commitment from all sections of society, right from the parents who should look after the health of their adolescent girls, prevent early marriage and spouse who should take good care of their kith and kin especially during pregnancy. The priority should be to create awareness among masses towards female health, to bridge the gap between government health resources and rural population by creating adequate cadres of health professionals and accessibility to health centres. Strict measures must be taken to prevent all sorts of malpractice by quacks in periphery like inadvertent use of syntocinon, misoprost, illegal and septic abortion which significantly affects maternal mortality counts especially in an underdeveloped state like Jharkhand. It is a high time when the Government as well as health professionals should take sincere efforts to upgrade the status of maternal health in Jharkhand as well as India.

\section{REFERENCES}

1. Special bulletin on maternal mortality in India 2010-2012: sample registration system, office of registrar general, India, 2013.

2. National rural health mission: framework for implementation 2005-2012. New Delhi: ministry of health and family welfare, Government of India.

3. United nations millennium development goals. www.un.org/millennium goals

4. United nations population fund, press release May, 2012.

5. Murthy BK, Murthy MB, Prabhu PM. Maternal mortality in a tertiary care hospital: a 10-year review. Int J Prev Med 2013;4(1):105-9.

6. Puri A, Yadav I, Jain N. Maternal mortality in an urban tertiary care hospital of north India. J Obstet Gynaecol India 2011;61(3):280-5.

7. Jain M, Maharahaje S. Maternal mortality: a retrospective analysis of ten years in a tertiary hospital. Indian J Prev Soc Med 2003;34:103-11. 
8. Jadhav AJ, Rote PG. Maternal mortality-changing trends. J Obstet Gynaecol India 2007;57:398-400.

9. Amitava P, Prasanta R, Samir H, et al. Review of changing trends in maternal mortality in a rural medical college in West Bengal. J Obstet Gynaecol India 2005;55(6):521-4.

10. Onakewhor JU, Gharoro EP. Changing trends in maternal mortality in a developing country. Niger J Clin Pract 2008;11(2):111-20.
11. Shah RJ, Ali I, Banday A, et al. Analysis of maternal mortality in a small teaching hospital attached to tertiary care hospital (A 10 year review). Indian J Community Med 2008;33(4):260-2.

12. Konar H, Chakraborty AB. Maternal mortality: a FOGSI study (based on institutional data). J Obstet Gynaecol India 2013;63(2):88-95. 